\title{
Prevalence of suicidal ideation and attempt: associations with psychiatric disorders and HIV/AIDS in post-conflict Northern Uganda.
}

\author{
James Mugisha, ${ }^{1,2,3}$, Herbert Muyinda ${ }^{2}$, Ashraf Kagee ${ }^{3}$, Peter Wandiembe ${ }^{4}$, Stephen Kiwuwa ${ }^{2}$ \\ Mpugu $^{3}$, Davy Vancampfort ${ }^{5,6}$, Eugene Kinyanda,
}

1. Kyambogo University, Kampala, Uganda

2. Makerere University, Child Health and Development Centre, School of Medicine, Mulago Hill, Kampala, Uganda

3. Stellenbosch University, Department of Psychology, South Africa

4. Department of Statistical Methods, Makerere University, COBAMS, Makerere Hill, Kampala Uganda

5. Department of Rehabilitation Sciences, University of Leuven, Leuven, Belgium

6. University Psychiatric Centre University of Leuven, Kortenberg, Belgium

7. MRC/UVRI Uganda Research Unit on AIDS, Uganda/MRC-DFID African Leadership Award, 50-59 Nakiwogo Street, Entebbe, Uganda

8. Department of Psychiatry, Makerere University College of Health Sciences, School of Health Sciences Makerere Hill, Kampala, Uganda

\begin{abstract}
:
Background: Research on the prevalence of suicidal ideation, attempt, and cormorbid psychiatric disorders in post-conflict areas is still limited.

Aim: We explored the prevalence of suicidal ideation, attempt, associated psychiatric disorders and HIV/AIDS in post-conflict Northern Uganda, an area that experienced civil strife for over two decades.

Methods: A total of 2400 respondents (aged 18 and above) and randomly selected in three districts

(Gulu, Amuru and Nwoya), were interviewed. Multivariable logistic regression was used to assess for associations between suicidality (suicidal ideation and attempt) and psychiatric cormorbidities.

Results: The prevalence of suicidal ideation and attempt were $12.1 \%$ and $6.2 \%$ respectively. Suicidality was significantly $(\mathrm{P}<0.001)$ higher among respondents with major depressive disorder (adjusted Odds Ratio $(\mathrm{OR})=9.5 ; 95 \% \mathrm{CI}=7.4,12.1)$ and post-traumatic stress disorder (adjusted $\mathrm{OR}=2.4 ; 95 \% \mathrm{CI}=1.6,3.6$ ). Men had lower odds of ideating or attempting suicide compared to women (adjusted OR $=0.55 ; 95 \%$ CI: 0.38, 0.82).

Conclusion: The prevalence rate of suicide ideation and attempt indicate a major public health problem in post-conflict Northern Uganda. Effective public mental health programs that that target both suicidality and psychiatric co-morbodities will be vital. Special attention should be given to women in post conflict Northern Uganda.
\end{abstract}

Keywords: Suicide attempt, ideation, cormorbidity, post-conflict Northern Uganda.

DOI: http://dx.doi.org/10.4314/ahs.v16i4.20

Cite as: Mugisha J, Muyinda H, Kagee A, Wandiembe P, Mpugu SK, Vancampfort D, Kinyanda E. Prevalence of suicidal ideation and attempt: associations with psychiatric disorders in post conflict Northern Uganda. Afri Health Sci2016;16(4): 1027-1035. http:/ / dx. doi.org/10.4314/ abs.v16i4.20

\section{Introduction}

Suicidal behaviour is a public health concern worldwide, affecting high, middle, and low income countries
Correspondent author:
James Mugisha,
Makerere University,
Child Health Development Centre,
School of Medicine, Makerere Hill,
Kampala, Uganda
P. O. Box 2958, Kampala, Uganda
Email: jmmugi77@hotmail.com

(World Health Organization (WHO), 2004; Corcoran et al., 2015). Although most of the risk factors for suicidal behaviour apply across different geographical areas, there are important contextual differences (Vijayakumar et al, 2005). However, data from the WHO mortality database indicate that $85 \%$ of the world's suicides occur in low and middle income countries (Krug et al., 2002). Despite this figure, little is actually known about the prevalence and risk factors of suicide across the African continent. In many African countries, developing indices of suicidal behaviour is difficult due to the absence of national death registers, poor records at service departments (including

African Health Sciences Vol 16 Issue 4, December, 2016 
police and medical facilities), civil conflict, culture and stigma among others (Kinyanda, 2011; Mugisha, 2012; De Leo et al., 2013). One of the established risk factors of suicidal behaviour is comorbid mental illness (Ovuga, Boardman \&Wassserman; 2005; Bellin \& Bruschi, 1996; Kinyanda et al. 2012). Data on the comorbidity of mental illness and suicidal behaviour in sub-Saharan African settings, especially those affected by political conflict is sparse. Nonetheless, the prevalence of mental disorders of major depression, post-traumatic stress disorder, and generalized anxiety has been found to be high in many post-conflict societies (De Jong, 2011; Karunakara et al., 2004).

Northern Uganda underwent a civil conflict (between government forces and Lord's Resistance Army rebels) for over two decades (1986-2006). Over 2 million people were displaced into internally displaced people's camps (IDPs) as a consequence of rape, torture, mutilation, destruction of property and many of the people including children were abducted (Roberts et al., 2008; Ovuga et al., 2008). Various studies have shown a high burden of mental disorders (Roberts et al., 2008, Ovuga et al., 2008, Vinck et al., 2007; Pfeiffer et al., 2011), ostensibly as a result of civil conflict. For example, Roberts and colleagues reported that $58 \%$ and $67 \%$ of their respondents had posttraumatic stress disorder (PTSD) and depression respectively amongst the internally displaced persons (IDPs). Pfeiffer et al. (2011) in their study among former abductees (in the same region) reported that $49 \%$ of respondents were diagnosed with PTSD, 70\% with symptoms of depression and 59\% with anxiety.

Suicidal behaviour may also be a sequela of these disorders although only a few studies have explored the prevalence of suicidal behaviour in conflict and post-conflict settings like Northern Uganda (e.g Ovuga, Boardman \& Wasserman, 2005; Kinyanda et al, 2013) and only one qualitative study, using psychological autopsy interviews, explored the relationship between suicide and alcohol abuse in post-conflict Northern Uganda (Kizza, 2013). To the best of our knowledge, there are no quantitative studies to date from conflict settings in sub-Saharan Africa that have explored the relationship between suicidal behaviour and co-morbid mental disorders.

The aim of this population-based study in post-conflict
Northern Uganda therefore was to explore the relationships between suicidal behaviour and major depressive disorder, post-traumatic stress disorder, generalized anxiety disorder, substance use disorder and HIV/AIDS. Next to this we aimed to explore socio-demographic factors associated with suicidal ideation and attempt.

\section{Methods}

Study design and setting

This study was conducted in three districts in Northern Uganda namely: Gulu, Nwoya and Amuru. This community survey was part of a baseline study for a project delivering a novel community-based intervention (Wayo-Nero project) to increase access to mental health services in post-conflict Northern Uganda. The project is supported by a grant from Grand Challenges Canada and Bill \& Merinda Gates foundation. Within each district, with the help of local leaders, all sub-counties were rated on how adversely they were affected by the 20 -year civil conflict from the most affected to the least affected (as guided by the local leaders). Two sub-counties, rated as most affected and had at least a level III health centre (based on the Ugandan health system) were selected from each participating district for the community-based intervention project.

\section{Sample size calculation}

A sample size of 400 respondents per sub-county was based on equal allocation of an overall sample of 2,400 which was calculated to ensure that the percentage of adults living with depression symptoms was estimated within $2.6 \%$ of the true value with $95 \%$ certainty. Depression was used to compute sample size because it was the most common mental disorder reported to be prevalent in Northern Uganda during active conflict (Roberts et al., 2008) and was one of the common mental disorders that was to be targeted by the current project (Wayo-Nero project). The proportion (p) of the population with symptoms of depression was considered as $29.3 \%$ from previous studies and the formula, (Kirkwood and Sterne, 2003), was used. A design effect (deff) of 2 and a response rate $(\mathrm{R})$ of $0.98 \%$ were assumed and a level of precision (m) was set at $2.6 \%$ as aforementioned.

\section{Sampling procedure}

Respondents were selected through a multi-stage cluster sample stratified on the sub-counties. Study respondents 
had to be residents in the six sub-counties and aged 18 years or more. In each sub-county a parish was randomly selected and a consecutive sample of individuals was chosen from all the villages within it. Since there was no reliable source of information on the number of households in each village, a sampling frame based on households was not possible. Using the Health Centre III or IV as the central point in each parish, teams of research assistants fanned out in the 4 directions of the compass to interview prospective study respondents. All adult members aged 18 years and above in homesteads lying along a village road in a given direction of the compass were visited and interviewed. Interviews in each parish were conducted until a total number of 400 eligible study respondents was attained (of the 2 sub-counties, the selected parish could not provide all the required 400 respondents so data collection was extended into the neighbouring parish of the same sub-county). Study interviewers were all psychiatric nurses who had received training into the objectives of the study, consenting procedures, administration of the study questionnaire, and the referral process for those respondents found to be distressed.

\section{Data collection tools}

We used the M.I.N.I. neuropsychiatric interview (MINI Plus) to assess for major depressive disorder (MDD), suicidality (ideation and attempted suicide), alcohol dependency/ abuse disorders, generalized anxiety disorder (GAD) and post-traumatic stress disorder (PTSD). The MINI Plus is a modular structured interview based on the DSM-IV(Sheehan et al., 1998) . HIV status was self-reported.

\section{Statistical analysis}

Data was analyzed using STATA software, Version 14. The survey design-adjusted (for stratification and clustering) effects. Chi-square tests were used to explore the associations between suicidality (ideation and attempt) and the different co-morbidities (MDD, PTSD, GAD, alcohol abuse or dependency and HIV status), and socio-demographics characteristics (age and sex). Multivariate logistic regression models were used to assess for multivariate associations between suicidality and the co-morbidities. In the multivariate logistic regression model, socio-de- mographic characteristics were excluded if the p-values associated with the corresponding regression coefficients were non-significant. This did not result in a significant change in the Akaike values information. The primary sampling unit (PSU) was the parish and the stratification variable was the sub-county. The sampling weights were based on the selection probabilities of the parishes.

\section{Ethical considerations}

Approvals were obtained from Makerere University College of Health Sciences, School of Medicine Ethics Committee. Ethical approval was also obtained from the Uganda National Council for science and Technology, the National Ethical Board as well as authorisation from all participating district administrative authorities. We obtained informed consent from all study respondents after explaining the objectives and procedures of the study. Respondents who were literate completed a consent form that was translated into the local dialect. Respondents who were not literate provided verbal consent as well as a thumb print on the consent form. Respondents were assured of confidentiality before the start of each interview. All data was collected was kept under key and lock and only accessible to the research team. Personal identifiers were not used at data entry. Study respondents found to have significant psychiatric problems were referred to the respective health centre in their sub-county, where psychiatric services had been boosted as part of the study.

\section{Results}

\section{Study population}

Data collection was carried out between $2^{\text {nd }}$ January 2013 and $2^{\text {nd }}$ June 2013. A total of 2,406 participants completed the study measurements (819 from Amuru district, 770 from Gulu district and 817 from Nwoya district). A total of 45 records were excluded from the analysis because of missing data on key variables, although these did not differ significantly from those retained on the basis of the study district, age and sex.

Of the total sample, 63\% were female and 69\% were married. Forty-nine percent (49\%) of respondents were aged above 34 years and $17 \%$ had attained higher than primary school education (Table 1 ). 
Baseline socio-demographic factors and prevalence of psychiatric disorders

\begin{tabular}{|l|l|}
\hline Characteristic & Number in study (N, \%) \\
\hline Sex & \\
\hline Male & $886(37.5)$ \\
\hline Female & $1475(62.5)$ \\
\hline Age group & \\
\hline $18-24$ & $552(23.8)$ \\
\hline $25-34$ & $628(27.1)$ \\
\hline $35-44$ & $479(20.7)$ \\
\hline $45-54$ & $659(28.4)$ \\
\hline Marital status & \\
\hline Currently married/cohabiting & $1649(69.1)$ \\
\hline Widowed & $294(12.3)$ \\
\hline Separated/Divorced & $172(7.2)$ \\
\hline Single & $273(11.4)$ \\
\hline Education level & \\
\hline No education & $569(23.9)$ \\
\hline Primary & $1423(59.7)$ \\
\hline Secondary and above & $393(16.5)$ \\
\hline HIV status (self-reported) & \\
\hline Negative & $2205(93.1)$ \\
\hline Positive & $164(6.9)$ \\
\hline GAD & \\
\hline No & $2051(85.2)$ \\
\hline Yes & $355(14.8)$ \\
\hline Alcohol dependency & \\
\hline No & $2244(93.3)$ \\
\hline Yes & $162(6.7)$ \\
\hline Alcohol abuse & \\
\hline No & $2241(93.1)$ \\
\hline Yes & $165(6.9)$ \\
\hline MDD current diagnosis & \\
\hline No & $1807(75.1)$ \\
\hline Yes & $599(24.9)$ \\
\hline PTSD diagnosis & \\
\hline No & $2389(87.7)$ \\
\hline Yes & $17(12.3)$ \\
\hline Suicidality status & \\
\hline Non suicidal & $2,090(87.4)$ \\
\hline Suicide ideation & $150(6.2)$ \\
\hline Suicide attempt & $156(6.4)$ \\
\hline
\end{tabular}


Seven percent $(7 \%)$ reported to be HIV positive while $15 \%, 25 \%$ and $12 \%$ were diagnosed with current episodes of GAD, MDD and PTSD, respectively.

The prevalence of suicidal ideation and attempt was 12.1 $\%$ and $6.4 \%$ respectively. The prevalence estimates of suicidal ideation and attempts among males in the sample were $4.1 \%$ and $4.5 \%$, respectively, while in females this was $7.4 \%$ and $7.6 \%$ respectively.

Suicidal ideation, attempt and co-morbidity with MDD, GAD, PTSD

Both suicidal ideation and attempts were significantly higher among individuals with MDD, GAD, PTSD and HIV/AIDS (Table 2) compared to those who did not have any of these disorders or HIV/AIDS. The odds of individuals with suicidal tendencies were almost ten times higher among the individuals with MDD (adjusted OR = 9.5; 95\%CI: 7.4, 12.1) and three times among individuals with PTSD (adjusted OR $=2.4$; 95\%CI: 1.6, 3.6) than among individuals without these conditions. Further, results in Table 2 also show that the higher the number of co-morbidities, the higher the odds that someone will think about, plan, or attempt suicide. Individuals with MDD, PTSD and GAD occurring together had thirty times the odds of ideating or attempting suicide $(\mathrm{OR}=$ 30.4; 95\%CI: 19.0, 48.5).

As can be seen in Table 2, men had lower odds of ideating or attempting suicide compared to women (adjusted $\mathrm{OR}=0.55 ; 95 \% \mathrm{CI}: 0.38,0.82)$.

Table 2: Suicidality and associated co-morbidities

\begin{tabular}{|c|c|c|c|c|c|c|}
\hline $\begin{array}{l}\text { Disorder/ } \\
\text { Characteristic }\end{array}$ & Non-suicidality & $\begin{array}{r}\text { Suicidality } \\
\text { (Ideation and } \\
\text { attempt) }\end{array}$ & $\begin{array}{r}\text { Unadjusted Odds } \\
\text { Ratio }(95 \% \text { CI) }\end{array}$ & p-value & $\begin{array}{l}\text { Adjusted Odds } \\
\text { Ratio }(95 \% \text { CI) }\end{array}$ & p-value \\
\hline \multicolumn{7}{|l|}{ MDD (general) } \\
\hline No & $1716(95.4)$ & $82(4.7)$ & 1.00 & & 1.00 & \\
\hline Yes & $374(63.3)$ & $224(36.7)$ & $12.06(9.67,15.05)$ & $<0.001$ & $9.48(7.42,12.11)$ & $<0.001$ \\
\hline \multicolumn{7}{|l|}{ GAD (general) } \\
\hline No & $1841(90.2)$ & $201(9.9)$ & 1.00 & & 1.00 & \\
\hline Yes & $249(70.8)$ & $105(29.2)$ & $3.79(2.97,4.84)$ & $<0.001$ & $1.23(0.96,1.59)$ & 0.107 \\
\hline \multicolumn{7}{|l|}{ PTSD (general) } \\
\hline No & $1895(90)$ & $217(10.1)$ & 1.00 & & 1.00 & \\
\hline Yes & $195(68.7)$ & $89(31.3)$ & $4.09(2.99,5.61)$ & $<0.001$ & $2.36(1.55,3.60)$ & $<0.001$ \\
\hline \multicolumn{7}{|l|}{ HIV status } \\
\hline Negative & $1930(87.8)$ & $272(12.1)$ & 1.00 & & 1.00 & \\
\hline Positive & $131(79.9)$ & $32(20.1)$ & $1.82(1.36,2.43)$ & $<0.001$ & $1.05(0.74,1.48)$ & 0.783 \\
\hline \multicolumn{7}{|l|}{ Alcohol abuse } \\
\hline No & $1954(87.6)$ & $277(12.4)$ & 1.00 & & 1.00 & \\
\hline Yes & $136(83.9)$ & $29(16.1)$ & $1.36(0.69,2.67)$ & 0.374 & $1.77(0.69,4.57)$ & 0.237 \\
\hline \multicolumn{7}{|l|}{$\begin{array}{l}\text { Combination of } \\
\text { disorders }\end{array}$} \\
\hline No disorder & $1517(96.2)$ & $59(3.8)$ & 1.00 & & & \\
\hline PTSD only & $87(91.3)$ & $8(8.7)$ & $2.43(1.26,4.72)$ & 0.009 & & \\
\hline GAD only & $81(91.0)$ & $9(9.0)$ & $2.52(1.14,5.55)$ & 0.022 & & \\
\hline MDD only & $196(66.8)$ & $101(33.3)$ & $12.71(9.15,17.66)$ & $<0.001$ & & \\
\hline GAD with PTSD & $31(81.8)$ & $6(18.2)$ & $5.68(2.23,14.46)$ & $<0.001$ & & \\
\hline MDD with GAD & $101(69.4)$ & 48 (30.6) & $11.27(7.3,17.36)$ & $<0.001$ & & \\
\hline MDD with PTSD & $41(55.7)$ & $33(44.3)$ & $20.32(12.6,32.63)$ & $<0.001$ & & \\
\hline All disorders & $36(45.7)$ & $42(54.3)$ & $30.36(19.0,48.48)$ & $<0.001$ & & \\
\hline \multicolumn{7}{|l|}{ Employment status } \\
\hline Not employed & $1,958(94.0)$ & $295(97.7)$ & 1.00 & & & \\
\hline Employed & $125(6)$ & $7(2.3)$ & $0.38(0.19,0.76)$ & 0.007 & & \\
\hline \multicolumn{7}{|l|}{ Religious affiliation } \\
\hline Catholics & $1,629(78.3)$ & $234(77.0)$ & 1.00 & & & \\
\hline Protestants & $264(12.7)$ & $40(13.2)$ & $1.03(0.63,1.71)$ & 0.893 & & \\
\hline Others & $188(9.0)$ & $30(9.8)$ & $1.08(0.75,1.58)$ & 0.669 & & \\
\hline \multicolumn{7}{|l|}{ Education } \\
\hline None & $483(85.7)$ & $82(14.4)$ & 1.00 & & & \\
\hline Primary & $1228(86.7)$ & $191(13.3)$ & $0.91(0.71,1.17)$ & 0.475 & & \\
\hline Above Primary & $360(91.9)$ & $31(8.1)$ & $0.53(0.37,0.76)$ & $<0.001$ & & \\
\hline \multicolumn{7}{|l|}{ Marital status } \\
\hline Married/cohabitating & $1456(88.8)$ & $188(11.3)$ & 1.00 & & & \\
\hline Widowed & $375(81.5)$ & $87(18.5)$ & $1.68(1.23,2.28)$ & $<0.001$ & & \\
\hline Single & $245(89.6)$ & $27(10.4)$ & $2.01(1.3,3.12)$ & $<0.001$ & & \\
\hline \multicolumn{7}{|l|}{ Sex } \\
\hline Female & $1244(85.0)$ & $227(15.0)$ & 1.00 & & 1.00 & \\
\hline Male & $810(91.4)$ & $70(8.6)$ & $0.53(0.39,0.72)$ & $<0.001$ & $0.55(0.38,0.82)$ & 0.003 \\
\hline \multicolumn{7}{|l|}{ Age group } \\
\hline 24 to 34 & $1031(88.0)$ & $144(12.0)$ & 1.00 & & 1.00 & \\
\hline 44 to 54 & $983(86.7)$ & $150(13.4)$ & $1.13(0.89,1.43)$ & 0.304 & $0.99(0.97,1)$ & 0.12 \\
\hline
\end{tabular}


Whereas at univariate analysis, being married was associated with lower odds of suicidality compared to being single or widowed, this association was non-significant in the multivariate analysis (Table 3).

\section{Table 3: Multivariate associations with suicide ideation and attempt}

\begin{tabular}{|l|l|l|}
\hline Disorder/Characteristic & $\begin{array}{l}\text { Unadjusted Odds } \\
\text { Ratio (95\% CI) }\end{array}$ & p-value \\
\hline MDD (general) & & \\
\hline No & 1.00 & \\
\hline Yes & $9.48(7.42,12.11)$ & $<0.001$ \\
\hline GAD (general) & & \\
\hline No & 1.00 & \\
\hline Yes & $1.23(0.96,1.59)$ & 0.107 \\
\hline PTSD (general) & & \\
\hline No & 1.00 & \\
\hline Yes & $2.36(1.55,3.60)$ & $<0.001$ \\
\hline HIV status & & \\
\hline Negative & 1.00 & \\
\hline Positive & $1.05(0.74,1.48)$ & 0.783 \\
\hline Alcohol abuse & & \\
\hline No & 1.00 & \\
\hline Yes & $1.77(0.69,4.57)$ & 0.237 \\
\hline Sex & & \\
\hline Female & 1.00 & \\
\hline Male & $0.55(0.38,0.82)$ & 0.003 \\
\hline Age group & & \\
\hline 24 to 34 & 1.00 & \\
\hline
\end{tabular}

\section{Discussion}

\section{General findings}

To the best of our knowledge, this is the first study in Uganda to report on suicidality (suicidal ideation and attempt) and its associations with psychiatric conditions (MDD, PTSD, alcohol abuse and dependence and generalized anxiety) and HIV / AIDS in post-conflict Northern Uganda, and in sub-Saharan Africa in general. The prevalence of suicidal ideation and attempts were $12.1 \%$ and $6.2 \%$, respectively. The odds of both suicidal ideation and attempts are significantly higher among individuals with MDD, GAD, PTSD and HIV/AIDS compared with those respondents who did not have the psychiatric conditions or HIV/ADS. Previous studies have indicated comorbidity between suicidality and psychiatric disorders, in particular with depression and PTSD (Wasserman et al., 1999; Ovuga et al., 2005; Kiyanda et al., 2015; Casey et al., 2006; Nock et al., 2008), though few studies have used

African Health Sciences Vol 16 Issue 4, December, 2016 formal diagnostic criteria (Wasserman et al., 1999) as in the current study. The high prevalence of major depressive disorder (at a rate of $24.7 \%$; Mugisha et al. 2015) and PTSD (at a rate of $11.8 \%$, Mugisha et al., 2015) could explain the high rates of suicide attempt and ideation.

We also acknowledge that definitions of suicide attempt differ and limit comparison of our findings with other studies (Wasserman et al., 1999; Ovuga et al., Kinyanda, 2006). However, the few epidemiological studies that have been undertaken in Uganda about suicidal ideation have reported higher prevalence rates than the ones currently reported in this study. Ovuga (2005) reported a suicide ideation rate of $13.6 \%$ conducted in two districts in Uganda (Adjuman and Bugiri). The reported higher suicide prevalence in that study could be partly explained by the observation that one of the study districts (Adjuman) was experiencing an active conflict in which communities experienced acute distress (Ovuga, 2005). 
Similarly, the few studies that have been conducted on suicidality in Uganda in people with self-reported HIV/ AIDS demonstrated also higher rates (e.g Kinyanda et al., 2011). More in detail, suicide ideation was reported in $12.4 \%$ and a suicide attempt in $17,1 \%$ of patients attending a specialized HIV/AIDS clinic before the antiretroviral treatment (ART) era in Uganda; while the suicidal ideation rate was $13 \%$ in the same setting in post-ART Uganda (Kinyanda et al., 2015). The reason for these higher rates could be explained by differences in location. The study of Kinyanda et al (2015) was conducted in urban Uganda while the present study took place in rural populations in Northern Uganda. Greater openness about suicidality was found previously in urban compared to rural populations (Mugisha, 2012, Ovuga et al., 2005). Related studies conducted in South-Africa (in an urban population) reported $16.8 \%$ of suicide ideation among HIV positive patients, $28.8 \%$ suicide ideation six weeks after an HIV test among those that had tested HIV positive (Schlebusch et al., 2012). However, due to a small number of respondents in our study that reported to be HIV positive, these findings should be treated with caution.

Our findings seem to concur with other studies that have found more females than males to be at a higher risk to both suicide attempt and ideation (Bosch, Schlebusch, Wessels, 1987;Minnaar, Schlebusch, Levin, 1979; Mengech and Dhadphale, 1984; Ndosi and Waziri, 1997; Pillay, Wassenaar, Kramers, 2001). Although some risk factors for suicide might be equally relevant to both genders, there are a number of other factors which may be more gender-specific. For example, differences between males and females have been reported in the prevalence, incidence, and morbidity risk of mental disorders with depression and anxiety more common in females and alcohol abuse and dependency more common in males. A possible reason for higher suicide attempt and ideation in females in our study might be that depression and anxiety rates were much higher than alcohol abuse and dependency rates in the researched post-conflict settings. It is known that depressive or anxiety disorders are a main reason for suicide attempt and ideation in females while in males; it is alcohol abuse disorder (McGirr et al., 2006; Monnin et al., 2012). Future research should however explore more in detail gender differences in suicidal expressions and attempts and their determinants.
The current data also show that those who were unemployed had a higher risk to both suicide attempt and ideation. It has been well documented previously (Schneider et al., 2011; Pompili et al., 2014) that unemployment may promote the vulnerability for suicidal behaviour. For example, it might add to the impact of stressful life events and other risk factors such as associated risk for mental illness, family conflict, financial difficulties with for example lack of financial resources resulting in unhealthy living conditions and the inability to seek adequate treatment (Schneider et al., 2011; Pompili et al., 2014). However, it might also be that poor mental health precedes and predicts both unemployment and suicide, thereby leading to a spurious link between unemployment and suicide. More longitudinal research is needed to disentangle the complex relationships between suicidality, mental illness and employment status.

Although age has been reported to be a risk factor for suicide ideation and attempt, also in people with HIV/ AIDS (Schlebush et al, 2012), we did not find such associations in a post-conflict setting. Similarly, in contrast with previous studies (Weissman et al., 1999), we did not find strong associations of marital status and suicide attempt in this study. Possibly because those who are not married could also find social support from relatives and other community members given the communal nature of Northern-Uganda.

\section{Practical implications of thestudy}

The high prevalence rates of suicidality and cormorbid mental disorders indicate the need to invest in health strategies and policies that can promote mental health and emotional well-being to address the prevalence rates of suicidality (Corcoran et al., 2015) in the study area. However, this strategic plan should have a strong component that entails effective management of the co-morbid conditions highlighted above and HIV/AIDS (Mugisha et al., 2015). A specific and well-tailored suicide prevention strategy and action plan for post-conflict Northern Uganda is vital as it has been done in some countries where some sections of the population have been more vulnerable to suicidal behavior (Corcoran et al., 2015). The suicide prevention strategy should entail at community and health systems levels, early identification of patients with a history of psychiatric disorder and those that might be grappling with HIV/AIDS. Functional welfare programs should be developed targeting those that have 
mental disorders and psychological distress along with their families. Referral networks should be developed between the formal health system and the informal networks at village levels including community and traditional leaders as many of the suicide attempters may not have come into contact with any formal mental health services in post-conflict Northern Uganda. Stigma reduction strategies targeting the general population, families and the health systems to increase acceptable of suicide attempters in the general population and at the health system are also necessary. Finally, the higher rates of suicidality prevalence reported in women indicate that special attention/care should be given to women in post-conflict suicide prevention programs To this end, a recent review (Krysinska et al., 2016) suggests that women tend to respond more to psychosocial treatments such as empowerment-focused psycho-educational group interventions, Dialectical Behavior Therapy, and Emotion Regulation Group Therapy than men,

\section{Limitations}

Suicide being a taboo subject implies that some informants could have feared to report on suicide ideation and attempt. We however believe a good interview environment was created in the current study (emphasizing confidentiality). Given the cross-sectional nature of the study, it was not possible to elucidate the direction of causality between suicidality and comorbid disorders of interest in this study. This could be better established through a longitudinal study design. Finally, we were not able to develop a sampling frame because there were no updated lists of community members at community level in most villages. This implies that the total sample might be a true representation of the target population.

\section{Conflict of interest}

None

\section{References}

Beautrais A,L1., Joyce P,R., Mulder R,T., Fergusson D,M., Deavoll B,J., Nightingale S,K (1996). Prevalence and comorbidity of mental disorders in persons making serious suicide attempts: a case-control study. Am J Psychiatry, 153(8):1009-14.

Bosch B,A., Schebusch, L., Wessels, W,H. (1987).Trends in adult parasuicide in an urban environment. $S A J P s y$ chol, 7(3), 100- 1005
Corcoran P., Griffin, E., O’Carroll, A., Cassidy, L., Bonner, B. (2015). Hospital-Treated Deliberate Self-Harm in the Western Area of Northern Ireland. Crisis. DOI: 10.1027/0227-5910/a000301

de Jong JT, Komproe IH, Van Ommeren M: Common mental disorders in postconflict settings. Lancet. 2003, 361 (9375): 2128 PubMed -2130. 10.1016/S01406736(03)13692-6.

De Leo D. Draper B.M. Snowdon J. Kolves K. Suicides in older adults:( 2013).A case-control psychological autopsy study in Australia. Journal of Psychiatric Research, (7):980-988. doi: 10.1016/j.jpsychires.2013.02.009

American Psychiatric Association. (1994). Diagnostic and Statistical Manual of Mental Disorders. American Psychiatric Association: Washington DC. Kiyanda, E., Wamala, D., Musisi, S \& Hjelmeland, H. (2011). Suicide in urban Kampala, Uganda: a preliminary exploration. Afr Health Sci.11(2):219-27.

Karunakara UK, Neuner F, Schauer M, Singh K, Hill $K$, Elbert T, et al. (2004). Traumatic events and symptoms of post-traumatic stress disorder amongst Sudanese nationals, refugees and Ugandans in the West Nile. Afr Health Sci. 4(2):83-93.

Kirkwood B, Sterne J. Medical Statistics. (2003.) Oxford, 2 ed. Blackweel Science: Hoboken, NJ, USA.

Kinyanda E, Hoskins S, Nakku J, Nawaz S, Patel V. Prevalence and risk factors of major depressive disorder in HIV/AIDS as seen in semi-urban Entebbe district Uganda. (2011). BMC Psychiatry. 11:205.

Kinyanda, E., Weiss, H.A., Mungherera, M., Onyango-Mangen, P., Ngabirano, E., Kajungu, R., Kagugube, J., Muhwezi, W., Muron, J., Patel, V. (2013). Prevalence and risk factors of attempted suicide in adult war-affected population of eastern Uganda. Crisis, 34(5), 314-323.

Kizza, D., Knizek, B.L., Kinyanda, E., Hjelmelandn H. An escape from agony: a qualitative psychological autopsy study of women's suicide in a post-conflict northern Uganda. (2012). Int JQual Stud Health Well-being;7:1-13.

Krug, E.G., Dahlberg, T.T., Mercy, J.A., Zwi, A.B., Lozano, R. (2002). World report on violence and health. World Health Organization, Geneva Krysinska, K., Batterham, P.J., Christensen, H. (2016). Differences in the effectiveness of psychosocial interventions for suicidal ideation and behaviour in women and men: a systematic review of randomised controlled trials. Archives of Suicide Research. Epub ahead of print.

McGirr, A., Seguin, M., Renaud, J., Benkelfat, C., Alda, 
M., \& Turecki, G. (2006). Gender and risk factors for suicide: Evidence for heterogeneity in predisposing mechanisms in a psychological autopsy study. Journal of Clinical Psychiatry, 67(10), 1612-1617.

Mengech HNK \& Dhadphale M. (1984) Attempted suicide (parasuicide) in Nairobi, Kenya. Acta Psychiatrica Scandinavica, 69: 416-419.

Milner A, De Leo D (2010). Who seeks treatment where? Suicidal behaviours and health care. Journal of Nervous and Mental Disease 198, 412-419.

Minnaar GK, Schlebusch L \& Levin A (1979) A current study of parasuicide in Durban. South African Medical Journal, 57: $204-207$.

Mugisha, J., Muyinda, H., Wadiembe, P., Kinyanda E. (2015). Prevalence and risk factors of Post Traumatic Stress Disorder seven years after the conflict in three districts in northern Uganda (The Wayo-Nero Study). BMC Psychiatry, 15, 70. DOI: 10.1186/s12888-0150551-5

Monnin, J., Thiemard, E., Vandel, P., Nicolier, M., Tio, G., Courtet, P., ... Haffen, E. (2012).

Sociodemographic and psychopathological risk factors in repeated suicide attempts: Gender differences in a prospective study. Journal of Affective Disorders, 136(1), 35-43. Ndosi NK \& Waziri MC .(1997). The nature of parasuicide in Dar es Salaam, Tanzania. Social Science Medicine, 44 (1): 55-61.

Roberts B, Ocaka KF, Browne J, Oyok T, Sondorp E. (2008). Factors associated with disorder and depression amongst internally displaced persons in northern Uganda. BMC Psychiatry, 8:38.

Pfeiffer A, Elbert T. PTSD, depression and anxiety among former abductees in Northern Uganda. (2011). Confl Heal. 5(1):14. 30.

Pompili M, Innamorati M, Di Vittorio C, Baratta S, Masotti V, Badaracco A, Wong P, Lester D, Yip P, Girardi P, Amore M.Unemployment as a risk factor for completed suicide: a psychological autopsy study. Archives of Suicide Research. 2014;18(2):181-92. PubMed

Schlebusch L, Vawda N: HIV-infection as a self-reported risk factor for attempted suicide in South Africa. (2010). Afr J Psychiatry., 13 (4): 280-283.

Schlebusch, L \& Govender, R, D. (2012). Age, Gender and Suicidal Ideation Following Voluntary HIV Counseling and Testing. Int J Environ Res Public Health. 9(2): 521-530.

Schneider B, Grebner K, Schnabel A, Hampel H, Georgi K, Seidler A. (2011). Impact of employment status and work-related factors on risk of completed suicide. A case-control psychological autopsy study. Psychiatry Research 190(2-3):265-70.

Steel, Z., Marnane, C., Iranpour, C., Chey, T., Jackson, J.W., Patel, V., Silove, D. (2014). The

global prevalence of common mental disorders: a systematic review and meta-analysis 1980-2013. International Journal of Epidemiology, 43(2), 476-493.

Ovuga, E., Boardman, J, Wassermann, D. (2005). Prevalence of suicide ideation in two districts of Uganda. Arch Suicide Res. 